\title{
Calculation and Analysis of Wind Power Consumption Capability of AC/DC Hybrid Grid
}

\author{
Jie Hao, Yongze Duan, Xinyuan Liu, Huiping Zheng
}

Electric Power Research Institute, State Grid Shanxi Electric Power Company, Taiyuan, China.

\begin{abstract}
The installed capacity of wind power in the "Three North" region is increasing day by day. Annual heating season is affected by peak shaving, and large-scale wind abandonment will occur in the "Three North" area. With the operation of UHV DCs in various regional power grids in China, the operation mode based on AC/DC hybrid power grids has gradually formed, providing a new delivery channel for new energy consumption in the "Three North" region. Based on the characteristics of thermal power, hydropower and wind power, this paper considers the various constraints in process of power transmission, builds a calculation and analysis model of wind power consumption capacity, and verified by the simulation.
\end{abstract}

Key words: UHV DC; wind abandonment; new energy consumption.

\section{Introduction}

As a renewable and clean energy source, wind power is mostly distributed in the "Three North" region of China. In recent years, with the gradual raise of wind power installed capacity, wind turbine power generation in China has also increased. Because winter is a period of wind power generation, limited by capacity of some sections and the peaking of heating units in power system, wind power consumption has A grim situation. Therefore, it is very important to optimize the power supply structure and flexibly adjust various resources so that the power grid can consume maximum wind power[1].

In terms of above problems, this paper combines the power generation characteristics of various power sources in Chinese power system, considers various constraints in the power grid, establishes a new energy consumption capacity analysis model, and applies the model for calculation with actual cases[2].

\section{The Calculation Model of Wind Power Consumption Capacity}

\subsection{Objective Function}

Considering the overall power generation of wind power, thermal power and hydro power, theobjective function is established by maximum wind power consumption, and the optimization model for wind power consumption is:

$$
\left\{\begin{array}{c}
\max T \sum_{i=1}^{N_{w}} \int_{0}^{P_{\text {wanax }}} F\left(P_{w}\right) d P_{w} \\
A\left(F, W, P_{w}\right) \in C
\end{array}\right.
$$

Where $\mathrm{T}$ is the calculation time; $\mathrm{Pw}$ is the wind power output; $\mathrm{F}$ is the thermal power unit output; $\mathrm{W}$ is the hydro power unit output; $\mathrm{A}$ is the probability density functional characteristic of types of unit; $\mathrm{C}$ is the constraint set;

\subsection{Wind Power Output Characteristics}

The actual output of the wind power plants is related to the wind speed in the region, which is proportional to the cube of actual wind speed in each region. Therefore, the actual output function of a wind power plant can be expressed as: 


$$
P_{w}(V)=\left\{\begin{array}{lc}
0 ? & V<v_{c i} \cup U>v_{c o} \\
\frac{P_{w r}}{v_{r}^{3}-v_{c i}^{3}} & v_{c i} \leq V \leq v_{r} \\
P_{w r} & v_{r} \leq V \leq v_{c o}
\end{array}\right.
$$

In the formula, $P_{w}$ is the wind power output; $v_{c i}$ is the cut-in wind speed; $v_{c o}$ is the cut-out wind speed; $v_{r}$ is the rated wind speed; $P_{w r}$ is the active power of the turbine at the rated wind speed; $\mathrm{V}$ indicates the actual wind speed in the wind area; and $P_{w}(\mathrm{~V})$ indicates the active power of turbine when the wind speed is V. In this paper, the rated power of a single turbine is $1.5 \mathrm{MW}$, the cut-in wind speed is $3 \mathrm{~m} / \mathrm{s}$, the rated wind speed is $12 \mathrm{~m} / \mathrm{s}$, and the cut-out wind speed is $25 \mathrm{~m} / \mathrm{s}$.

\subsection{The Constraints of Power System}

(1). constraints in power balance

$$
\left\{\begin{array}{l}
P_{i}-V_{i} \sum_{j=1}^{N} V_{j}\left(G_{i j} \cos \delta_{i j}+B_{i j} \sin \delta_{i j}\right)=0 \\
Q_{i}-V_{i} \sum_{j=1}^{N} V_{j}\left(G_{i j} \sin \delta_{i j}-B_{i j} \cos \delta_{i j}\right)=0
\end{array}\right.
$$

(2). constraints in units output

$$
\left\{\begin{array}{l}
P_{G i \min } \leq P_{G i} \leq P_{G i \max } \\
Q_{G i \min } \leq Q_{G i} \leq Q_{G i \max }
\end{array}\right.
$$

In the formula, $P_{G i \max }, P_{G i \min }$ represent the maximum and minimum active power of single thermal power unit, $Q_{G i \max }, Q_{G i \min }$ represent the maximum and minimum reactive power of single thermal unit.

(3). constraints of nit climbing speed

$$
\begin{aligned}
& P_{t h n, i, t}-P_{t h n, i, t-1} \leq P_{t h n, i, \max } \\
& P_{t h n, i, t}-P_{t h n, i, t-1} \leq P_{t h n, i, \text { min }}
\end{aligned}
$$

In the formula, $P_{t h n, i, \max } \quad P_{t h n, i, \min }$ are lifting and processing rate limit of thermal power unit i.

(4) Constraints in unit peaking coefficient

1) Heating period

a. Heating unit: $P C_{U H} \leq 0.26$

b. Non-heating unit: $P C_{H} \leq 0.45$

2) Non-heating period

During the non-heating period, the peaking coefficients of all types of units are basically same.

(5)Constraints in hydro power unit

$$
\left\{\begin{array}{l}
S C_{h n, j, t+1}=S C_{h n, j, t}+R_{h n, j, t}-H\left(P_{h n, j, t}\right) \\
S C_{h n, j, \min } \leq S C_{h n, j, t} \leq S C_{h n, j, \max }
\end{array}\right.
$$

Among them, $S C_{h n, j, t+1}, S C_{h n, j, t}$ represent reservoir capacity of $\mathrm{t}+1$ and $\mathrm{t}$ respectively, $R_{h n, j, t}$ is the water storage capacity, $H\left(P_{h n, j, t}\right)$ is the function of water usage in power generation; $S C_{h n, j, \min }$, $S C_{h n, j, \max }$ are upper and lower limits of storage capacity.

\subsection{Calculation Method}

Considering the basic situation of load determination, the grid is divided into several areas according to the section. Based on above constraints, the Monte Carlo algorithm can obtain the optimum solution on wind power output, the conventional unit output and the conventional unit startstop status in the AC/DC power system when thermal power has the minimum power-on mode[3-4]. 


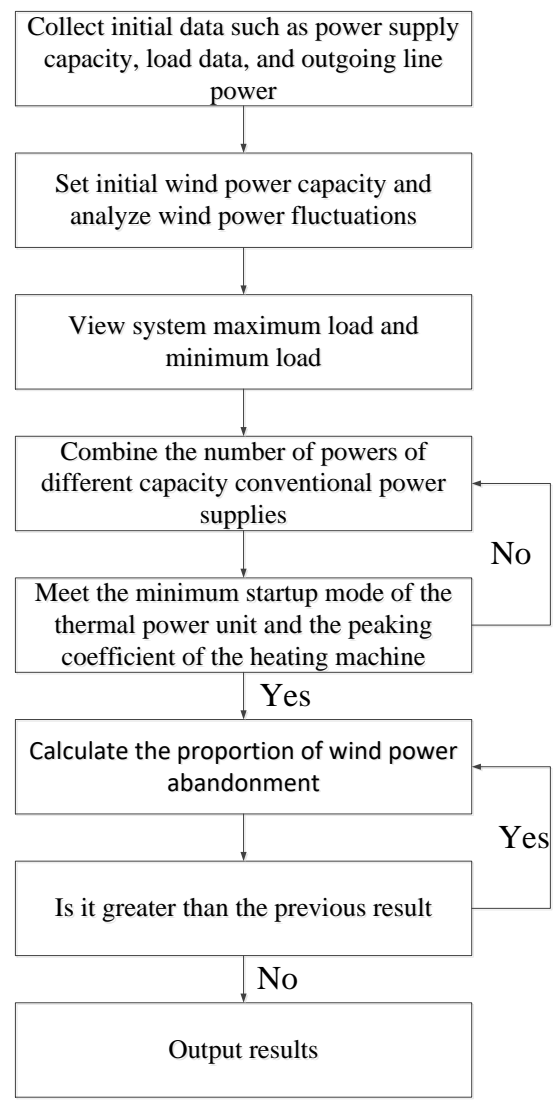

Fig.1 Simulation process

\section{Example Simulation}

\subsection{Study Description}

According to the actual grid structure and data of Shanxi Province, the actual installed capacity of wind power in Shanxi Province had exceeded 10 million kilowatts in 2017, and the Yanhuai highvoltage DC line had been newly put into operation. Due to the changes in the grid structure of the Shanxi province in the second half of 2017, this paper decide to simulate the condition of the first half of 2017 in Shanxi. In the first half of 2017, wind power in Shanxi Province was blocked in north areas where more wind turbines were installed, what was mainly affected by section and peak shaving. Among them, the obstruction of the section mainly include the $220 \mathrm{kV}$ main transformer capacity of the Shuitou and the thermal stability of the $220 \mathrm{kV}$ Shuoshui line. Therefore, the northern power grid of the province is divided into three areas for calculation, there are Shui-tou area, 220kV Xin-shuo area, $500 \mathrm{kV}$ main network and the $220 \mathrm{kV}$ ring network in Datong and the south-central area.

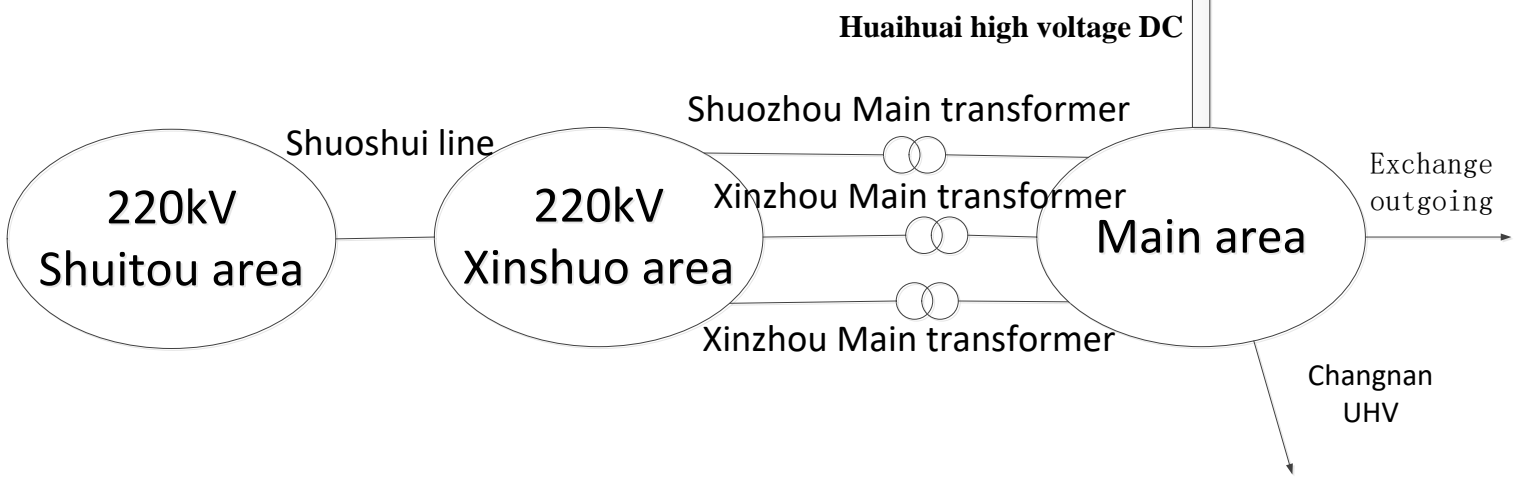

Fig. 2 Network frame structure diagram 
The section of the $220 \mathrm{kV}$ Xinshuo area, the $500 \mathrm{kV}$ main network and the $220 \mathrm{kV}$ ring network in Datong and the south-central part is Shuozhou main transformer, main transformer of Xinzhou as well as the main transformer of Wuzhai. The section limit is the sum of $220 \mathrm{kV}$ side limit of Shuozhou main transformer, $220 \mathrm{kV}$ side limit of Xinzhou main transformer and $220 \mathrm{kV}$ side limit of Wuzhai main transformer. The total section limit is 4 million kilowatts; The section of the Shuitou area and the Xinshuo area is the Shuoshui line, and the section limit is 600,000 kilowatts of the Shuoshui line limit.

\subsection{Boundary Conditions}

\section{(1) Load data}

This paper applies regression analysis to predict monthly load data; the load growth rate is about $5 \%$ according to the actual situation in 2017, which is basically the same as the actual situation.

(2) System Rotation

The system rotation capacity is calculated based on $5 \%$ of the maximum daily load;

(3)Thermal power start mode

The minimum cycle of start-stop of a thermal power unit is one week;

(4) Delivery section data

The AC outgoing contact line uses the peak low valuation of the province annual plann delivery; the UHV DC delivery uses the planned transaction power of the province and the receiving province.

(5) Wind power installed capacity in wind speed simulator

Due to the large difference in seasonal wind speeds in various regions of the province, the average wind speed sequence in the region is used in each region; the installed capacity of wind power uses the actual installed capacity of the province.

(6) Constraints when hydropower participates in power balance

The minimum output of the hydropower unit during the dry season is 0 , the maximum output is 0.6 , the minimum output is 0 during the flood season, the maximum output is full; the pumped storage power station unit runs at full capacity; there is no constraint on the balance of power.

\subsection{Analysis on Calculation Results}

In the first half of 2017 , the wind power generation capacity was 7.868 billion $\mathrm{kWh}$, which had $1 \%$ error with actual power generation; the wind power utilization hours were 986.6 hours approximately, which had $1 \%$ error with actual utilization hours; the abandoned wind power was about 9.0 billion $\mathrm{kWh}$, and the deviation was $4.25 \%$. Among them, the Xinshuo area abandoned wind power is 521 million $\mathrm{kWh}$, the Shuitou area abandoned wind power is 242 million $\mathrm{kWh}$, the Datong and southcentral areas abandoned wind power is 138 million $\mathrm{kWh}$, as shown in Table 1 . Through the analysis of above problems, the conclusions have little deviation from the actual results.

Table 1. The analysis on new energy consumption of Shanxi power grid in 2017

\begin{tabular}{|c|c|}
\hline Calculation of power generation (100 million kwh) & 78.68 \\
\hline Actual power generation (100 million kwh) & 77.95 \\
\hline Computing utilization hours (h) & 986.6 \\
\hline Actual utilization hours (h) & 975.8 \\
\hline Calculation of discarded wind / photoelectricity (100 million kwh) & 9.00 \\
\hline Actual discarded wind / photoelectric volume (100 million kwh) & 9.41 \\
\hline Rate of discarding (\%) & $10.26 \%$ \\
\hline
\end{tabular}

\subsection{Sensitivity Analysis}

(1) Sensitivity analysis of wind resources

Compared with the basic case, wind power is limited to 116 million $\mathrm{kWh}$, an increase of 216 million $\mathrm{kWh}$ with an increase of $10 \%$ in wind resources, . In the case of a $10 \%$ reduction in wind 
resources, wind power is limited to 728 million $\mathrm{kW}$, declined 172 million $\mathrm{kWh}$. The specific data is shown in the table 2.

Table 2. The results of sensitivity analysis of wind resources

\begin{tabular}{|c|c|c|c|}
\hline & $\begin{array}{c}\text { Utilization hours of wind } \\
\text { power resources(h) }\end{array}$ & $\begin{array}{c}\text { Power generation } \\
(100 \text { million kwh })\end{array}$ & $\begin{array}{c}\text { Discarded wind (100 } \\
\text { million kilowatt hours })\end{array}$ \\
\hline Basic case & 986.6 & 78.68 & 9.00 \\
\hline $\begin{array}{c}\text { The increase of wind } \\
\text { resources by 10\% }\end{array}$ & 999.42 & 81.07 & 11.16 \\
\hline $\begin{array}{c}\text { The reduction of wind } \\
\text { resources by 10\% }\end{array}$ & 902.95 & 68.27 & 7.28 \\
\hline
\end{tabular}

(2) Load sensitivity analysis

Sensitivity analysis was performed at $50 \%, 60 \%, 80 \%$, and $90 \%$ of the current growth rate compared to the base case. With a load of $50 \%$ of the current growth rate, the wind power limit is 765 million $\mathrm{kWh}$, a reduction of 135 million $\mathrm{kWh}$; with the load is $60 \%$ of the current growth rate, and the wind power limit is 710 million $\mathrm{kW}$, increase of 190 million $\mathrm{kWh}$; with the load is $80 \%$ of the current growth rate, the wind power limit is 672 million $\mathrm{kWh}$, a decrease of 238 million $\mathrm{kWh}$; with the load is $90 \%$ of the current growth rate, the wind power limit is 645 million $\mathrm{kWh}$, a drop of 255 million $\mathrm{kWh}$. The specific data is shown in the table 3.

Table 3. Load sensitivity analysis of Shanxi power grid in 2017

\begin{tabular}{|c|c|c|}
\hline & Power generation $(100$ million $\mathrm{kwh})$ & Discarded wind (100 million kilowatt hours) \\
\hline Basic case & 78.68 & 9.00 \\
\hline $50 \%$ of the growth rate & 79.88 & 7.65 \\
\hline $60 \%$ of the growth rate & 80.43 & 7.10 \\
\hline $80 \%$ of the growth rate & 81.82 & 6.72 \\
\hline $90 \%$ of the growth rate & 82.08 & 6.45 \\
\hline
\end{tabular}

\section{Conclusion}

With the development of economy, large-scale wind power will be further integrated into the grid system. The consumption capacity depends mainly on the comprehensive coordination of the whole network system and whether it can flexibly adjust resource utilization. Based on the consideration of power transmission peaking and other constraints, this paper solves the feasible solution of wind power maximum consumption in large AC/DC power grids. Through the analysis of Shanxi Power Grid, it can be concluded:

1) Different flexible adjustment resources such as increasing load demand can improve wind power consumption.

2) The biggest problem restricting the ability of wind power consumption is the peaking capacity of the heating unit is insufficient. Therefore, increasing the peaking capacity of thermal power units is the main measure to improve the consumption capacity of wind power within the province.

\section{References}

[1]. ZHANG Yong. Study of wind power accommodated capability of power grid based on time sequence simulation[D]. Chengdu: Southwest Jiaotong University,2012.

[2]. FAN Pengfei, ZHANG Lizi, XIE Guohui. Analysis model for accommodation capability of wind power with adequacy resources involved in system regulation[J]. Power System Technology, 2012, 36(5): 51-57. 
[3]. WAGNER H J, EPE A. Energy from wind - perspectives and research needs [J]. European Physical Journal Special Topics, 2009, 176(1): 107-114.

[4]. LIU Chang, WU Hao, GAO Changzheng, et al. Study on analysis method of accommodated capacity for wind power [J]. Power System Protection and Control, 2014, 42(4): 61-66. 